\title{
CLARÍN Y LA CRÍTICA FEMINISTA
}

\author{
Isabel NAVAS OCAÑA \\ Universidad de Almería
}

Las primeras lecturas en clave feminista de la obra de Clarín, y en concreto de La Regenta, el texto más comentado, apuntan hacia explicaciones de carácter sociohistórico de la problemática del adulterio. Biruté Ciplijauskaité lo considera el primer síntoma de la ruptura del contrato matrimonial y de la desintegración de la familia. Por esa razón, "la mayor parte de las novelas 'burguesas' del siglo XIX se desenvuelven alrededor del tema de la familia imperfecta como contraste a la novela anterior" (1984: 43)1. Lou Charnon-Deutsch (1990) también observa en Clarín y en Galdós una intensa preocupación por la crisis de las dos instituciones burguesas básicas: el matrimonio y la familia. Para hacer frente a esta crisis, ambos defienden la educación de la mujer. Participan de la idea krausista de que una mujer educada puede cumplir mejor su papel dentro de la institución familiar, sobre todo en lo que se refiere a la educación de los hijos. Contribuyen así a reforzar la "ideología de la domesticidad", el modelo femenino del "ángel del hogar" (Aldaraca, 1992), que no es en realidad sino una estrategia de contención de las nacientes aspiraciones feministas. De ahí que en estos primigenios atisbos de crisis de la institución familiar Ciplijauskaité observe un hecho fundamental: las mujeres se van a rebelar no tanto contra el marido como contra la sociedad. El punto de partida de Ana Karenina, Madame Bovary y Ana Ozores es su deseo de evasión del aburrimiento, de la monotonía de la rutina diaria, de una existencia enjaulada sometida a reglas precisas (1984: 48). De hecho, Lisa Gerrard culpa a la misógina sociedad del XIX de la opresión de la mujer y de su destrucción. La Regenta es, en su opinión, a devasting picture of the devaluation and oppression of women (1987: 91), de la disintegration of an intelligent, sensitive woman in a misogynistic society (Ibid.: 95). Pero Gerrard va más allá y plantea incluso la identificación de Clarín con el personaje de Ana Ozores, his intuitive sympathy for a female character oppressed by sexist attitudes and institutions (Ibid.: 91). Según Gerrard, la opresiva vida provinciana que padece la Regenta la vivió también Clarín. Como Ana, Clarín es un artista al que la corrupción de la vida política e intelectual llega a desalentarle tanto que se plantea incluso el hecho de dejar de escribir. Por eso, Gerrard concluye que "In a novel concerned with the struggle between artist and society, Alas has rendered the artist's dilemma as a woman's persecution by sexist attitudes. Hence, the sympathetic rendering of her opression and the feminism that colors the confrontation between artist and society" (Ibid.: 96). En definitiva, no se trata sólo de demostrar la simpatía de Clarín hacia una mujer cuyas iniciativas son sistemáticamente frustradas por una sociedad misógina que condena su sexualidad y su inteligencia, ni se trata sólo de ver en Ana Ozores el alter ego de Clarín², sino de convertir los conflictos femeninos en símbolo del enfrentamiento del artista con la sociedad, aspecto éste de gran trascendencia en la literatura decimonónica desde el romanticismo a las teorías

\footnotetext{
${ }^{1}$ Ciplijauskaité hace un análisis comparativo de Ana Karenina de Tolstoi, Madame Bovary de Flaubert, La Regenta de Clarín y Effi Briest de Fontane.

${ }_{2}$ Asunto también apuntado por la crítica feminista: la frustración de todos los personajes es un reflejo de la frustración personal de Clarín. De aqui su mordacidad (Ciplijauskaité, 1984: 51).
} 
del arte por el arte (Navas Ocaña, 1999: 192-212). Ahora bien, para sostener esta tesis Gerrard se ve en la obli-gación de hacer frente al antifeminismo de Clarín, mostrado públi-camente en textos como Psicología del sexo (1894), donde da argumentos biológicos para justificar los papeles tradicionales atribui-dos a cada sexo ${ }^{3}$, en novelas como Su único hijo (1890) y Teresa (1895) o en la polémica relación que mantuvo con Emilia Pardo Bazán. Gerrad habla de un proceso evolutivo que conduce a Clarín desde el liberalismo y el krausismo de juventud al conservadurismo de su madurez. En ese proceso Clarín oscila entre una inicial simpatía hacia la educación femenina, idea de origen krausista que inspira según Gerrard el feminismo de La Regenta, y posiciones más tradicionales presentes en Su único hijo y en Teresa. Pero no se debe olvidar que las teorías krausistas sobre la educación femenina vinieron a reforzar la reclusión de la mujer en el ámbito de la domesticidad y que, por esa razón, no están tan lejos como a primera vista podría pensarse del determinismo biológico con el que Clarín define las diferencias entre los sexos. Además, otras críticas feministas, como Sara E. Schifter (1982) y Elena Gascón Vera (1992), han visto también ese determinismo en la caracterización del personaje de Ana Ozores: la maternidad frustrada es la principal razón aducida a lo largo de la novela para justificar, que no perdonar, el adulterio ${ }^{4}$. Schifter observa el mismo planteamiento determinista en la insistente presentación de Ana como una mujer al borde de la locura. Y arremete directamente contra Clarín por expresar los conflictos sociales feme-ninos en términos de enfermedad mental: uch women are punished by society and by the authors who describe them as being on the verge of insanity whenever they confront their multiple conflicts 1982: 233).

El feminismo en su versión humanista y liberal, del que hacen gala aquí tanto Ciplijauskaité como Schifter y Gerrard, es un feminismo emparentado con las tesis realistas de Lukàcs, con la exigencia de que la obra literaria refleje una experiencia humana de carácter represen-tativo en su contexto social ${ }^{5}$. No ha de sorprendernos, por tanto, que junto a causas sociológicas o históricas estas críticas feministas recurran con frecuencia a aspectos biográficos y que interpreten siempre en términos colectivos la experiencia individual, tanto la del personaje como la de su autor. Por eso, La Regenta se convierte en la expresión literaria de la crisis de la institución familiar, de la opresión de la mujer en una sociedad misógina y del enfrentamiento entre el artista y la sociedad. Y todo ello apoyado en argumentos biográficos: la influencia de las ideas krausistas en Clarín, sus tensas relaciones con la vida intelectual y política de la época, su frustración, su conser-vadurismo de madurez, etc. Pero lo curioso, y lo verdaderamente interesante, es que, en pos de la teoría del reflejo, de una teoría que apuesta por el realismo, por el verismo de la representación, la actitud de Clarín en La Regenta llegue a ser enjuiciada de forma totalmente diferente, contradictoria incluso. Mientras Lisa Gerrard defiende el

\footnotetext{
${ }^{3}$ Según Clarín, la objetividad, la innovación y el altruismo son rasgos que sólo los genera la actividad del órgano masculino y, en consecuencia, tareas como la política, las artes o las ciencias sólo serán posibles al hombre, mientras que la mujer ha de replegarse a la vida familiar, a la conservación de las tradiciones y del hogar.

${ }^{4}$ Según Schifter, he novelist's view of the female's need for maternity as both a biological and psychological imperative echoes the traditional patriachal judgment on female destiny (1982: 237). Y Gascón Vera afirma: asimismo, en relación con Ana Ozores y su falta de hijos, el autor parece indicar que la maternidad podría haber sido su salvación y que es la ausencia del hijo lo que le lleva a aburrirse y verse tentada por el adulterio (1992: 166).

${ }^{5}$ Toril Moi demostró estas relaciones en un ensayo emblemático: "Quién teme a Virginia Woolf? Lecturas feministas de Woolf" (1987).
} 
feminismo de la novela y lo justifica con un dato que se pretende objetivo (el liberalismo del joven Clarín), Sara Schifter niega ese feminismo con una estrategia similar (la presencia de las teorías clarinianas sobre el determinismo biológico en la representación de Ana Ozores). Un mismo planteamiento realista produce por tanto conclusiones bien distintas. Este tipo de crítica que en ningún caso se cuestiona la existencia de una única verdad en el texto, de la que el autor es el garante último ${ }^{6}$, no duda tampoco en ofrecer su lectura de ese texto como si se tratase de la única y verdadera lectura posible. Confrontar, sin embargo, estas verdades absolutas no nos conduce sino a la convicción de su relativismo.

No faltan, por supuesto, estudios que aborden la problemática de la locura y del biologismo desde una perspectiva psiquiátrica o psico-lógica. De hecho, Bridget A. Aldaraca (1990) y Jo Labanyi (1991) han examinado la histeria en el personaje de Ana Ozores como manifestación patológica de un matrimonio carente de sexualidad. Pero antes de entrar de lleno en estas lecturas voy a comentar algunos aspectos interesantes planteados por la crítica feminista de raigambre realista, humanista y liberal en torno a la sexualidad femenina. Tanto Sara Schifter como Lisa Gerrard denuncian el tratamiento negativo dado en La Regenta a la sexualidad femenina. Por ejemplo, la aventura con Germán en la barca tiene consecuencias dramáticas para Ana ya que se interpreta como un escándalo. Según Schifter, desde entonces Ana asocia la sexualidad con un intenso sentimiento de culpabilidad, de temor y con una cierta repugnancia (1982: 232). Para Gerrard, que también repasa estos acontecimientos de la infancia de Ana Ozores, la misógina sociedad del XIX considera la sexualidad femenina como algo problemático, conflictivo, criminal: a woman is perpetually on the verge of criminality, even if she is only a child (1987: 92). Noël Valis señala, por otra parte, la constante asociación en La Regenta de la sexualidad con imágenes escatológicas de las cuales el sapo es la suprema instancia. Pues bien, el beso final del sapo lo interpreta Valis como el símbolo de la definitiva separación de Dios, de la condena de Ana al infierno. Se insiste, por tanto, en la idea de la sexualidad femenina como criminalidad, como pecado.

No pocas críticas feministas han destacado la importancia de la Iglesia en La Regenta como reflejo de la gran influencia del estamento eclesiástico en la sociedad española de la época. Según Biruté Ciplijauskaité, Clarín se desvía del triángulo amoroso clásico y opta por el rectángulo, poniendo en el primer plano no la vacilación entre el marido y el seductor, sino la lucha entre dos rivales (Álvaro Mesía y Fermín de Pas), y de esa forma enfrenta el poder civil y el eclesiástico (...), mostrando que en los dos casos se trata menos de la conquista de una mujer que de la dictadura de la ciudad (1984: 56). Gascón Vera piensa que el adulterio no es nada más que el pretexto para la exposición de las fuerzas falocéntricas del poder erótico que ejerce el hombre sobre la mujer (1992: 156). Esas "fuerzas falocéntricas" son el poder mundano, representado por don Álvaro, y el poder espiritual, representado por don Fermín. Y Gascón Vera puntualiza: En La Regenta estos poderes universales (...) parecen condenados y denigrados. Pero una lectura femenina podría constatar que, a pesar de la crítica del autor, éste también acepta la fuerza de estos poderes, ya que los hace triunfar a través de la realidad del rechazo y del abandono en que se verá sumida la mujer al final de la novela (Ibid.). De nuevo la crítica feminista condena la actitud de

\footnotetext{
${ }^{6} \mathrm{Y}$, por eso, se le pueden pedir cuentas, como hace Schifter, se le puede acusar de una conducta reprobable.
} 
Clarín, de nuevo se evidencia aquí el carácter realista de una parte de esta crítica, que cree ver en la obra el reflejo de la experiencia de su autor. Sara Schifter destaca también la dimensión colectiva, sociológica, que tiene el triángulo amoroso formado por Ana, Álvaro y Fermín. A Schifter le parece un juego o una cacería con dos cazadores y una víctima: Ana. Y es un juego en el que toma parte toda Vetusta, pues cada uno de los contrincantes tiene sus seguidores (el Casino y Visitación por parte de Álvaro, y la iglesia y doña Petronila por parte de Fermín). Algunos de ellos, como Visitación o la marquesa de Vegallana ayudan a ingeniar la seducción de Ana y se alegran cuando ésta se ha consumado porque así la virtud de la Regenta ya no las deja en entredicho ${ }^{7}$. Los hombres también parecen contentos. Según Gerrard, la caída final de La Regenta en brazos de su amante es vista por Vetusta como una confirmación de la debilidad de la mujer y Gerrard vuelve a insistir en la misoginia de una sociedad que exige castidad a las mujeres pero al mismo tiempo cree firmemente que la castidad es algo imposible en ellas (1987: 94). Ciplijauskaité llama la atención sobre el hecho de que Clarín es el único que salva a la protagonista de la muerte, que no le impone la muerte como castigo, a diferencia de Flaubert, Tolstoi y Fontane. Sin embargo, su castigo es, en opinión de Ciplijauskaité, aún más cruel: En realidad, la pena es mayor: debe enfrentarse a la sociedad que antes la halagaba y la envidiaba, quedando totalmente sola y pobre (1984: 65). Otra vez se pone en entredicho la actitud del escritor.

En relación con esta cuestión del final de la novela, voy a detenerme en las teorías de Bridget A. Aldaraca, que traen a colación la intensa crítica hecha al psicoanálisis desde el feminismo. Aldaraca comienza señalando la relación del título de su trabajo "El caso de Ana O." con el famoso caso de Anna O. que inicia Los estudios sobre la histeria de Breuer y Freud, publicados diez años después de La Regenta. Intenta establecer de esta forma un paralelismo entre el discurso narrativo de la novela realista y naturalista y el discurso científico decimonónico, cimentado en el positivismo, que está en la base del psicoanálisis freudiano. Estos dos tipos de discurso confían plenamente en la objetividad de sus planteamientos $\mathrm{y}$, en consecuencia, niegan la subjetividad del científico y del escritor. Aldaraca lo llama "la desubjetivación o la cosificación del agente del acto científico" (1990: 60). Y, sin embargo, Aldaraca evidencia el lenguaje metafórico, literario, narrativo, empleado por algunos médicos para describir los síntomas de la histeria, y al mismo tiempo compara el relato de la vida de Ana Ozores con "el estudio de un organismo en un experimento de laboratorio" (lbid.: 56), atendiendo especialmente al ambiente social que rodea a ese organismo y que determina su comportamiento y su conducta patológica. El fanatismo religioso, la estrecha moral social de la aristocracia en una ciudad de provincias, los condicionantes económicos que la conducen a un matrimonio sin amor con un hombre mucho mayor que ella, son factores decisivos para que Ana desarrolle la enfermedad de la histeria. La frustración de sus deseos sexuales a causa de la impotencia de su marido, don Víctor Quintanar ${ }^{8}$ es una de las razones de sus ataques histéricos, aunque

\footnotetext{
${ }^{7}$ Aún así son simples peones en la lucha masculina por el poder: Women play important roles in the noble city of Vetusta, but principally as pawns in a struggle for political or religious power over each other or physical or emotional dominance over women (Charnon Deutsch, 1990: 78). La Regenta, y Vetusta en un nivel más amplio, aparecen sólo como objetos de dominación masculinos. Por eso, para Charnon- Deutsch la torre de la Catedral, desde la que Fermín de Pas contempla toda la ciudad, no es sino a phallic symbol of his will-to-dominate the feminine city (Ibid.).

${ }^{8}$ Aldaraca es tajante al respecto: las destaca la importancia de la vida sexual del matrimonio haciéndonos entender que el ex-regente Victor Quintanar, es y siempre ha sido impotente (Ibid.: 56).
} 
Aldaraca insiste en que "Alas pone el amor en todas sus manifestaciones bajo su microscopio" (Ibid.: 57), y añade como otros posibles motivos la pérdida del amor filial durante la infancia con la muerte de los padres. Pero quizás lo más interesante sea la explicación que ofrece del episodio final de la novela, cuando Ana se desmaya y la besa furtivamente Celedonio, el acólito. Aldaraca relaciona el episodio con otro caso de histeria descrito por Freud, el de Dora. Freud tardó varios años en publicar el historial de esta mujer porque ella lo abandonó y se quedó sin el desenlace médico previsible: la curación o la muerte. Que Ana despierte de su desvane-cimiento, que tenga que volver a casa y seguir viviendo contradice, según Aldaraca, el desenlace médico que para las historias de adulterio había adoptado la novela realista hasta ese momento, la muerte: "El historial clínico sólo tiene dos posibles desenlaces, o la curación o la muerte. Cualquiera de los dos nos permite olvidarnos de la enferma, olvidar su historia. En el mundo de la novela del XIX, Emma Bovary tranquiliza al público conservador francés, suicidándose, Ana Karenina nos resuelve el problema de su existencia dejándose aplastar por el tren. Pero Ana despierta de su pesadilla para encontrarse todavía en ella. Y no tendrá más remedio que volver a su casa y seguir viviendo" (Ibid.: 60-61).

Aldaraca parece indicar que la mujer se resiste a dejarse encasillar en los patrones médicos, psicológicos, sociales y literarios del XIX. Obsérvese cómo importa muy poco que quien plantee ese desenlace sea un hombre (Clarín), porque Aldaraca, al evidenciar la pretensión de objetividad en el psicoanalista y en el novelista decimonónico, no sólo la pone en entredicho sino que se distancia de aquellas corrientes críticas de carácter realista que analizan la obra como reflejo de su autor. La lectura de Aldaraca, instalada ya de pleno en el horizonte postestructuralista, no cree en la existencia de un significado estable en la obra literaria, del que el autor aparezca como garante, sino que apuesta por que sea el lector quien construya ese significado. Es lo que ella hace.

En cambio, la crítica feminista que parte de presupuestos humanistas y realistas ha destacado el carácter estereotipado de Ana Ozores. Si una lectura en clave postestructuralista, dominada por el relativismo y el subjetivismo, conduce lógicamente hacia la individualización del personaje, una lectura en clave realista, asentada en el concepto de lo típico, de lo representativo, termina sin más remedio en el estereotipo. Schifter, por ejemplo, describe a Ana Ozores como “arquetipo trágico femenino"(1982: 230) y Lisa Gerrard, que la ve como símbolo de la frustración femenina en una sociedad machista, se detiene en las imágenes cosificadas que de ella ofrecen otros personajes de la novela. Su padre, por ejemplo, la contempla "como si fuese el arte", "como si no tuviera sexo". Para sus tías no es sino un objeto en el mercado matrimonial al que hay que engordar para que la ganancia sea mayor. Y la ciudad la considera por su belleza, junto con la torre de la catedral y el paseo, como una de "las tres maravillas de la población" (1987: 92). Además, el único modo de superar su insatisfacción sexual es a través de la religión llegando a convertirse, según Gerrard, en el fiel reflejo de un modelo en este caso literario: La perfecta casada de Fray Luis de León (1987: 93). Catherine Jagoe (1988) utiliza también un arquetipo, la imagen bíblica del ángel caído, para explicar la capitulación final de la Regenta, la mutilación de Tristana y la muerte de Fortunata. Y Lou Charnon-Deutsch (1990) observa que la representación de la mujer en la narrativa clariniana es la de un adversario: las figuras femeninas con frecuencia simbolizan los obstáculos que impiden la maduración social de los personajes masculinos y además se las define a partir de la idea de la determinación biológica. Otro es- 
tereotipo femenino del que la crítica se ha ocupado es el de la madre fálica. Tal calificativo merece, según Gascón Vera, la madre del Magistral ya que se comporta como un símbolo de lo masculino actuando siempre sin emotividad hacia el hijo y viendo en él la realización de sus ambiciones y la réplica y continuación de su vida dura e implacable donde el poder y el dinero son lo más importante (1992: 166). Y no faltan tampoco interesantes reflexiones sobre los modelos masculinos presentes en La Regenta, con especial atención a la quiebra de patrones clásicos como el don Juan o el marido burlado (Ciplijauskaité, 1984: 84-89). A nuevas relaciones familiares y sociales corresponden nuevos tipos humanos. Ésta es la tesis de Ciplijauskaité, que utiliza la expresión "el don Juan desdonjuanizado" para referirse a "la demolición del don Juan tradicional" (Ibid.: 84): Clarín presenta a un Álvaro Mesía ya algo mayor, que ha de administrar sus fuerzas, que tiene mala puntería y que es un cobarde, como demuestra su huida final. En cuanto al 'marido burlado', Ninguno, salvo Karenin, odia al seductor. Es más: inconscientemente, en un punto u otro, ayudan en la tarea de seducción, introduciendo un elemento cómico o grotesco (Ibid.: 89). La ingenuidad, la mediocridad y la bondad son algunos rasgos de Víctor Quintanar. Clarín lo muestra con frecuencia alentando a don Álvaro para que conquiste a Ana. Su reacción, cuando conoce el adulterio, es literaria: Clarín lo llama "espadachín lírico", no tiene intención de matar a nadie (planea tirar a las piernas) y no cree que don Álvaro sea capaz de alcanzarle a tanta distancia. Pero Clarín lo hace sucumbir a la fatalidad no de un honroso y fatal disparo al corazón sino de un balazo en la vejiga.

La crítica feminista inspirada en el materialismo cultural ha hecho una importante objeción al feminismo humanista tradicional responsable de lecturas arquetípicas como las que acabamos de mostrar. Es la siguiente: los personajes femeninos y los masculinos son analizados como si encarnasen una esencia homogénea y ahistó-rica, y esto supone aceptar la eternidad de las distinciones de género y, en consecuencia, asumir la imposibilidad de acabar con las desigual-dades que estas distinciones vienen alimentando desde hace siglos (Newton y Rosenfelt, 1985: xvi-xvii; apud Sagarra y Carabí, 2000: 43-46). Presentar a la Regenta como el emblema de la tragedia, de la frustración, de la caída de la mujer -así, en singularconlleva en cierta forma la implícita aceptación de que es ésa justamente la esencia femenina. Sin embargo, no hay que menospreciar, en mi opinión, el valor de este tipo de crítica, propia de una fase inicial de desarrollo del feminismo y por ello interesada en hacer visible la difícil situación de las mujeres en una sociedad dominada durante mucho tiempo por valores patriarcales. Y habría que incluir además una precisión respecto al trabajo de Ciplijauskaité. Aunque su perspectiva es realista ya que presenta los nuevos paradigmas mascu-linos como un reflejo del cambio que se está produciendo en las relaciones familiares del XIX, se aproxima un tanto a la crítica feminista materialista al remitir esos arquetipos a imágenes no eternas sino concretas, pertenecientes a una época, históricamente bien delimitadas.

Por otra parte, la crítica de naturaleza semiótica, inspirada en las teorías de Bajtin sobre la ficción, y la crítica deconstructiva han producido también interesantes acercamientos a La Regenta, relacionados en la mayoría de los casos con el lugar que la literatura (San Agustín, Santa Teresa, Chateabriand, Don Juan Tenorio, etc.) tiene en la obra. Por ejemplo, Diane F. Urey explica la pasión de Ana Ozores por los libros como la búsqueda de la propia identidad. Por eso, Ana reescribe esos libros y los hace hablar de 
acuerdo con sus deseos, creándose así un "endless intertextual process" (1990: 36) ${ }^{9}$. Y por eso también, cuando Álvaro la abandona y ella sucumbe al dolor y a la enfermedad, renuncia a la lectura y a la escritura, y esa renuncia la interpreta Urey como un símbolo de su muerte (Ibid.: 42). Además, la indagación constante de una identidad y la imposibilidad de establecerla las coloca Urey en paralelo con el proceso mismo de la narrativa ${ }^{10}$. De igual forma, la figura de Celedonio, que espía a la Regenta mientras lee y que después la besará al final de la novela, no es para Urey sino un trasunto del lector y un magnífico ejemplo de las tesis derrideanas sobre el lenguaje: el lenguaje no representa la realidad sino que la difiere, evidencia no su presencia sino su ausencia ${ }^{11}$. Elena Gascón Vera hace una perspicaz observación sobre The Fate of Reading and Other Essays (1975) de Geoffrey Hartman, que muy bien podría aplicarse a esta figura del lector masculino (Celedonio) y al libro-mujer (Ana) que él lee: "la mayoría de los críticos asumen que el lector típico es un hombre y algunos, como Geoffrey Hartman, comparan el leer al placer que el hombre siente al mirar a las chicas en cuyo proceso, según él, uno se siente perjuro, asesino, truculento, lleno de culpa. Así pues las mujeres, que teóricamente también al leer se basan en sus propias experiencias, no pueden sentir el placer de mirar a los chicos, sino, más bien, la desazón de ser miradas, de considerarse las chicas humilladas, restringidas y marginadas por la mirada del otro" (Ibid.: 157-158).

En definitiva, la identidad de Ana Ozores es un proceso sin fin de búsqueda presidido por una intertextualidad infinita que, salvando las distancias, ejemplifica muy bien el proceso mismo de la narrativa, y al que sólo puede poner fin el lector. De ahí que Catherine Sieburth (1987) afirme que La Regenta contiene múltiples versiones literarias de su pro-pio argumento ${ }^{12}$. La conflictiva personalidad femenina de Ana Ozores queda entonces atrapada en el lenguaje, en la literatura, como ente ficcional perfectamente individualizado cuya representatividad sólo puede ser leída en términos literarios. Es más, según Sieburth, la continua oscilación entre el estereotipo literario y la singularización del personaje evidencia la energía entrópica de la obra, su naturaleza dialógica (Ibid.: 290). El feminismo humanista, en cambio, interpreta la pasión de la Regenta por la lectura y la escritura como una secreta vía de escape, como un refugio contra la vida sin sentido a la que es condenada por la sociedad machista (Schifter, 1982: 230-236 y Gerrard, 1987: 92-93). Pero la sociedad veta incluso esa salida censurando la dedicación de la mujer a la literatura. Como apunta Ciplijauskaité, "el descubrimiento de que Anita escribe poesía causa consternación en todos los sectores" (1984: 71). La Regenta aparece entonces como el símbolo de las dificultades femeninas para acceder a la escritura ${ }^{13}$, para poseer un lenguaje propio ${ }^{14}$. El texto de

\footnotetext{
${ }^{9}$ As the reader looks to other texts in search for a more complete reading of La Regenta, so Ana seeks fulfillment for the loss of her mother and satisfaction of her spiritual and physical yearnings in books, both the ones she reads and the ones she writes, like the poems and novels of her youth (Ibid.:36-37).

${ }^{10}$ Ana's efforts thus reiterate and reflect the processes of character, plot and interpretation that constitue the narrative (Ibid.: 30).

${ }^{11}$ This first scene, then, of Ana reading, is at a distance from the observer/reader and the 'present' of the narrative, which is only another optical illusion. Ana is representating, just like the book she is reading. Her presence is a figment of Celedonio's imagination, deferred through the spy glass and throug time" (Ibid.: 32). Y continua: "Words dissimulate the absence of reality, just as Ana's image reveals no real presence and La Regenta is only a book, not reality (Ibid.: 33).

${ }^{12}$ Por ejemplo, The relationship between Santa Teresa and her confessor is the impetus for all possible variants of relations between the clergy and women. There are Obdulia's relations with the Bishop of Nauplia; Olvido's mystic love for Don Fermin; Fermin's relations with Teresina and Petra; his domination of Sor Teresa (Ibid.: 281). Y todas ellas, por supuesto, como un trasunto de la relación entre Ana y don Fermín.

${ }^{13}$ The message is clear: female creativity outside of the female capacity to create life in the womb is inappropiate and borders on scandal (Schifter, 1982: 236).
} 
nuevo se interpreta como reflejo de la situación real de la mujer. En un caso Ana, ser fragmentario y dividido, queda aprisionada en el lenguaje, en la metaliteratura, en la metaficción; y en otro, su imagen (su esencia única, homogénea y coherente) se fija en un espejo en el que quizás es ella la única que no se reconoce.

Pero si hay dos lecturas que jueguen un papel fundamental en La Regenta son el Don Juan Tenorio y Santa Teresa. Las teorías psicoanalíticas sobre la psicología femenina, tanto las freudianas como las lacanianas, van a estar presentes en el sugestivo análisis que James Mandrell (1990) realiza sobre la 'malevolent' presencia del drama de Zorrilla y de la mística en La Regenta. Como Bridget A. Aldaraca, Mandrell parte de la estrecha relación entre las investigaciones psicoanalísticas y las de la novela realista y naturalista del XIX ${ }^{15}$. Según Freud, la mujer, inferior por naturaleza al hombre, posee un menor sentido de la justicia, es incapaz de sublimar sus instintos y sus intereses sociales son exiguos. En ella el complejo de Edipo se resuelve en el ansia de posesión del poder masculino y patriarcal. Por eso, como apunta Lacan, es una ausencia que no puede convertirse en presencia. Para Lacan, los hombres y las mujeres existen únicamente en el lenguaje, y las mujeres, como ausencia, sólo son objeto de las fantasías masculinas. Mandrell, que ve en Álvaro y en Fermín "two avatars of Don Juan" (Ibid.: 19), utiliza estas teorías para explicar la función del texto donjuanesco en la novela: «The absence that is woman is filled with the presence that is man and patriarchal desire at the same time that Ana's "wants" are supposedly fulfilled by Fermín de Pas and Álvaro Mesía, which is to say, La Regenta is filled with Don Juan Tenorio» (Ibid.: 8). Ahora bien, puesto que la mujer es ausencia, el placer femenino lo coloca Lacan más allá del falo y lo relaciona con la mística ${ }^{16}$. El deseo místico, «this non-phallic jouissance» se caracterizaría por «the combination of sexual experience with the lack of sexual knowledge» (Ibid.: 7), y estaría presente en La Regenta gracias a la figura de Santa Teresa. Don Juan y Santa Teresa constituyen así "the two extremes of desire" en la novela (Ibid.: 21), llegando incluso a entrar en conflicto. No en vano el Magistral teme que la lectura de Santa Teresa lo aparte de Ana. Pero Mandrell ve en este otro tipo de deseo una variante más del masculino, tanto por la relación amorosa que el Magistral tiene con Sor Teresa como porque Ana acaba cayendo si no en los brazos de Fermín, en los de Álvaro, y abandonando sus lecturas místicas. Santa Teresa se convierte entonces en un reflejo de Doña Inés, la novicia que muere y salva al seductor ${ }^{17}$. Y, por ello, mientras la novela finaliza con la muerte so-

\footnotetext{
${ }^{14}$ Según Charnon-Deutsch, en La Regenta what much separates men from women are the power and uses of speech. Women speak, of course, but their utterances are rigidly patterned, repetitive, and unoriginal (1990: 82). Y cita las reflexiones de Luce Irigaray sobre el lenguaje femenino para refrendar esta idea: The words Irigaray speaks to her unnamed female interlocutor could be instructively directed to Ana as a reminder of what her speeches do not communicate to us: 'Taking one model after another, passing from master to master, changing face, form, and language with each new power that dominates you. You/we are sundered; as you allow yourself to be abused, you become impassive travesty' (This Sex 210). Ana's greatest shortcoming is that she fails to find a way out of the exile of self that the various discourses have read into her. She has not been able to put her desire into words free of the play of discourses (sexual, romantic, religious) that hold her fast to the gaze of the other (Ibid.: 97).

${ }^{15}$ What are Anna Karenina, Madame Bovary, and La Regenta, to give only three examples, if not considerations of and answers to the question, 'What does woman want?'. In the other words, the subject that Freud was to explore in the 'scientific' terms of psychoanalysis, novelist in the realist tradition were exploring in the language of fiction (Ibid.: 5).

${ }^{16}$ The quintaessential expression of the unknowable pleasure that is associated whit the woman is to be found in mystic desire as it is experienced by woman and men, since there are men who are just as good as women (apud Mandrell, ibid.: 7).

${ }^{17}$ There is, therefore, in the world of La Regenta, no femenine model of desire that stands apart from the masculine other. Everything is contingent on masculine models of desire whereby the feminine exists only as a projection of the desires of men. In this context, Santa Teresa inevitably becames like Don Juan's Doña Inés, the text of seduction and salvation (Ibid.: 23).
} 
cial de Ana, Álvaro y Fermín pueden continuar con sus vidas y sus conquistas. En este sentido a Mandrell le parece que Clarín es «less sympathetic manner than Lacan» (Ibid.: 23), aunque la conclusión del psicoanálisis y de Clarín sea, en su opinión, la misma: "To be sure, the marginality of the protagonist and eponymous heroine of the novel as it is effected by the narrator and author of La Regenta corresponds to the marginalizing and patriarchal tendencies of the psychoanalytic theories of Freud and Lacan..." (Ibid.: 23-24). Esta lectura psicoanalítica, que concluye abjurando del psicoanálisis, evidencia por un lado las siempre controvertidas relaciones del psicoanálisis con el feminismo, y por otro la importancia que para la crítica psicoanalítica tiene el autor. No en vano Mandrell termina por hacer responsable a Clarín de la transmutación del deseo femenino en una variante más del masculino, convirtiéndolo en el principal aval de la verdad del texto, una verdad que, aunque leída en términos metaliterarios (no perdamos de vista que el objetivo primordial es dilucidar el papel de Don Juan Tenorio en la novela), no deja de ser única y acaba por aparecer como representativa del sometimiento de la mujer a los poderes patriarcales, y entre ellos, al psicoanálisis, tanto el freudiano como el lacaniano. Por esta razón, el análisis de Mandrell no está tan lejos de la crítica feminista humanista. De hecho, desde esa crítica se han señalado también modelos femeninos religiosos que escapan a la autoridad masculina. Según Sara E. Schifter, Ana Ozores aprende a superar su insatisfacción sexual mediante el éxtasis místico, desarrollando al mismo tiempo una gran devoción por la Virgen, a la que dedica poemas y plegarias. Pues bien, para Schifter, la Virgen representa la imagen de una mujer separada del dominio masculino, imagen que proporciona la posibilidad de una identidad femenina libre de las normas patriarcales y lejos por fin del tópico de la fémina diabólica ${ }^{18}$.

En definitiva, desde la sociología literaria al materialismo cultural, pasando por el psicoanálisis, la semiótica o la deconstrucción, el feminismo ha recorrido un largo y apasionante camino, y La Regenta lo ha recorrido con él.

\section{REFERENCIAS BIBLIOGRÁFICAS}

Aldaraca, Bridget A. (1990). "El caso de Ana O.: histeria y sexualidad en La Regenta", Asclepio, 42, julio, 51-61.

- (1992). El ángel del hogar: Galdós y la ideología de la domesticidad en España, Madrid (Visor).

Andreu, Alicia (1996). "La crítica feminista y las obras de Benito Pérez Galdós y Leopoldo Alas", Breve historia feminista de la literatura española (en lengua castellana). Iris M. Zavala (coord.). Barcelona (Anthropos), III, 31-48.

Ciplijauskaité, Biruté (1984). La mujer insatisfecha. El adulterio en la novela realista. Barcelona (Edhasa).

Charnon-Deutsch, Lou (1990). Gender and Representation. Women in Spanish Realist Fiction, Amsterdam - Filadelfia (John Benjamins Publishing Co).

\footnotetext{
${ }^{18}$ The May symbol has given Catholic women (as opposed to Protestant women who have denied Mary's divinity) the possibility of a spiritual identity independent of patriarchal rule. The sanctification of the Virgin thus mitigates the power of the myth of femenine evil and frees woman of the need to be saved by the male (1982: 233).
} 
Durand, Frank (1990). "Structure and the drama of role-playing in La Regenta", Malevolent Insemination and Other Essays on Clarín, ed. Nöel Valis. Ann Arbor, Michigan (University of Michigan), pp.141-154.

Gerrad, Lisa (1987). "The Feminist Dimension in La Regenta", Letras femeninas, Vol. XIII, no 1 y 2, pp.91-99.

Jagoe, Catherine (1988). Ambiguous Angels: Gender in the Novels of Galdós, Northen Illinois University.

Mandrell, James (1990). "Malevolent Insemination: Don Juan Tenorio in La Regenta", Malevolent Insemination and Other Essays on Clarín, ed. Nöel Valis. Ann Arbor, Michigan (University of Michigan), pp.1-28.

Moi, Toril (1987). Teoría literaria feminista, Madrid (Cátedra), 1988.

Navas Ocaña, María Isabel (1999). Teoría de la literatura británica y norteamericana I. De la antigüedad grecolatina al siglo XIX. Almería (Servicio de Publicaciones de la Universidad de Almería).

Newton, Judith y Rosenfelt, Deborah (1985) (eds.). Feminist Criticism and Social Change: Sex, Class and Race in Literature and Culture, Nueva York y Londres (Methuen).

Ortiz Aponte, Sally (1971). Las mujeres de "Clarín": esperpentos y camafeos, San Juan de Puerto Rico (Universidad de Puerto Rico).

Sánchez, Elizabeth D. (1990). "Beyond the realist paradigm: subversive strategems in La Regenta and Madame Bovary", Malevolent Insemination and Other Essays on Clarin, eed. Nöel Valis. Ann Arbor, Michigan (University of Michigan), pp.101-116.

Schyffer, Sara E. (1982). “La loca, la tonta, la literata: Women's Destiny in Clarín's La Regenta", Theory and Practice Feminist Literary Criticism, eds. Gabriela Mora y Karen S. Van Hoof. Ypsilanti, Michigan (Biligual Press / Editorial Bilingüe), pp.229-241.

Segarra, Marta y CARABÍ, Ángels (2000) (eds.). Feminismo y crítica literaria, Barcelona (Icaria).

Semprúm Donahue, Moraima de (1973). "La doble seducción de La Regenta”, Archivum, 23, Oviedo, pp.11-33.

Sieburth, Stephanie (1987). “Interpreting La Regenta: Coherence vs Entropy, Modern Language Notes 102, 2, pp.275-291.

- (1990). "Kiss and tell: the toad in La Regenta. Malevolent Insemination and Other Essays on Clarín", ed. Nöel Valis. Ann Arbor, Michigan (University of Michigan), pp.87-100.

Urey, Diane F. (1990). “Writing Ana in Clarín's La Regenta”, Male-volent Insemination and Other Essays on Clarín, Ed. Nöel Valis. Ann Arbor, Michigan (University of Michigan), pp.29-45.

Valis, Nöel Maureen (1984). “Sobre la última frase de La Regenta”, Clarín y La Regenta en su tiempo. Actas del simposio internacio-nal. Oviedo (Universidad de Oviedo), pp.795-808. 